OPEN ACCESS

Edited by:

Matthias Jaeger,

Psychiatrie Baselland, Switzerland

Reviewed by:

Sonja Mötteli,

Psychiatric University Hospital

Zurich, Switzerland

Vicky Stergiopoulos,

Centre for Addiction and Mental Health (CAMH), Canada

*Correspondence:

Stefanie Schreiter

Stefanie.schreiter@charite.de

${ }^{\dagger}$ These authors share first authorship

Specialty section: This article was submitted to Public Mental Health a section of the journal Frontiers in Psychiatry

Received: 12 January 2021 Accepted: 07 May 2021 Published: 08 June 2021

Citation: Gutwinski S, Westerbarkey E, Schouler-Ocak M, Moran JK and

Schreiter S (2021) Housing Satisfaction of Psychiatric Patients in Different Forms of Housing $-A$

Cross-Sectional Study in Berlin,

Germany.

Front. Psychiatry 12:652565. doi: 10.3389/fpsyt.2021.652565

\section{Housing Satisfaction of Psychiatric Patients in Different Forms of Housing-A Cross-Sectional Study in Berlin, Germany}

\author{
Stefan Gutwinski ${ }^{1,2 \dagger}$, Ella Westerbarkey ${ }^{2 \dagger}$, Meryam Schouler-Ocak ${ }^{1,2}$, James K. Moran ${ }^{2}$ \\ and Stefanie Schreiter ${ }^{2 *}$ \\ ${ }^{1}$ Department of Psychiatry and Psychotherapy, Psychiatrische Universitätsklinik der Charité im St. Hedwig-Krankenhaus, \\ Berlin, Germany, ${ }^{2}$ Charité-Universitätsmedizin Berlin, Corporate Member of Freie Universität Berlin, Humboldt-Universität \\ zu Berlin, Department of Psychiatry and Psychotherapy, Berlin Institute of Health, Berlin, Germany
}

The growing social problem of homelessness and precarious housing situations has negative effects on psychological outcomes and quality of life (QoL) for mentally ill people. Despite a large body of research on QoL among homeless mentally ill people, research on housing satisfaction as a specific QoL domain and important outcome variable for treatment interventions is scarce. The purpose of this cross-sectional study is to investigate housing satisfaction among psychiatric patients in various housing situations. Out of 1,251 patients that were treated in the targeted facilities during the admission period, 540 agreed to participate (43.2\%). 123 participants were excluded from the analysis due to missing data, resulting in a sample of $N=417$. Housing satisfaction data was assessed in a subjective screening and differences in satisfaction levels between housing status groups were analyzed. As hypothesized, more normative housing situations reported higher housing satisfaction. Homeless participants and those living in socio-therapeutic facilities were associated with more psychological and physical distress resulting from their housing situation than domiciled and flat-sharing participants. Problems of reducing homelessness and improving housing support are highlighted, as well as opportunities for improving support, particularly in therapeutic facilities.

Keywords: homelessness, mental illness, precarious housing, therapeutic facility, quality of life, housing quality, housing satisfaction

\section{INTRODUCTION}

The deinstitutionalization and reformation of the psychiatric system in Germany in the 1970s aimed at improving the living conditions of people with mental illness by creating residential care facilities $(1,2)$. As a result, an increasing number of psychiatric patients now live in community settings and housing facilities, and a great body of research has been conducted to evaluate those settings and conditions $(1,3)$. A potential unintended consequence of this is that the deinstitutionalization of mental health care is nowadays associated with a growing number of people with mental illness living in precarious living conditions, as its association with a greater social, cultural, political and work-related exclusion is discussed $(2,4)$. 
Such marginalized living circumstances are negatively associated with psychological wellbeing (5-8). Quality of life (QoL) measures have increasingly been used in psychiatric research in recent years to understand how mentally ill people experience non-institutionalized settings (9-11). Several studies reported that higher QoL in persons with mental illness is more generally associated with normative housing conditions. This encompasses community-based residences and family homes that foster independence, stability and commonness, as opposed to state hospitals (12-14). Focusing mainly on clients in therapeutic psychiatric facilities, studies found that clients in assisted living accommodation reported lower levels of life satisfaction than the general population (15). Increasing QoL was found to be interrelated to type of housing: whereas low QoL could be linked to large institutional settings, higher measures were associated with a "normalization" of the housing situation in sheltered accommodation (13).

Additionally, some authors argue that the deinstitutionalization can be considered one of the causal factors for the growing social problem of homelessness, as patients were released from hospitals without the necessary support to live on their own (16-18). The marginalized group of homeless people experiences discrimination, social exclusion, segregation from support networks and a lack of insurance, income and social support (16, 17, 19-22). Furthermore, homelessness is associated with significantly more mental and physical health problems compared to the non-homeless population; and with poorer negative health-related prognoses, a reduced effectiveness of recovery, and higher mortality in people with mental disorders $(18,19,23,24)$.

Previous studies on QoL in regard to housing circumstances showed that homeless persons and psychiatric patients, but most strikingly homeless people with a mental disorder report a significantly lower QoL than the general population $(5,9,17)$. Additionally, homeless mentally ill samples reported lower QoL in several life domains, including finances, friends and family, as compared to domiciled and community-based care patients $(19,25,26)$.

Despite fundamental research on QoL and homelessness or therapeutic facilities, comparative data of a range of housing forms in mentally ill samples is lacking. An adequate differentiation between different types of housing and homelessness is frequently overlooked (e.g., sleeping at other people's places). For example, being at risk of homelessness could have comparable associations with mortality and prevalence of psychiatric disorders as homelessness itself $(17,27,28)$. A distinction between various types of housing for people with mental illness, such as living in therapeutic facilities or in at-risk-of-homelessness situations could give insight into specific challenges and needs of different housing circumstances. Further, this could help target approaches for minimizing the stress of mentally ill people individuals.

Although results suggest that housing satisfaction (HS) as a subscale of QoL may be an important outcome in its own and an important predictor of further outcomes, most studies focus on general QoL assessments rather than domain-specific analyses (29). Housing itself, however, plays a central role in the treatment of mentally ill people and constitutes a stabilizing basis for everyday functioning, social integration, health, and participation $(28,30)$.

Therefore, this study examined HS measures among psychiatric in-patients in different housing settings. It was hypothesized that people in more precarious and less normative housing situations would report lower HS.

\section{METHODS}

\section{Study Design and Participants}

The study is part of the "WOHIN" project, a cross-sectional survey designed to investigate the housing situation, psychiatric morbidity and service use among psychiatric in-patients and dayclinic patients treated in the catchment area of the Psychiatric University Hospital Charité at St. Hedwig Hospital over a 6months period (15th March-15th September 2016) [see further details in $(31,32)]$. The hospital offers in-patient treatment for 192 patients on three general psychiatric wards, four specialized wards, and 5 day-clinics. The study was approved by the local ethics committee of the Charité Berlin (Number: EA1/291/15).

A total number of 1,251 patients were admitted and contacted by trained interviewers soon upon admission. 540 (43.2\%) were willing to participate. A monetary incentive $(5 €)$ was offered, interviews averaged $1 \mathrm{~h}$. All participants gave written consent before participating.

From the original sample, 120 participants were excluded because important data for the analyses were missing. Three participants who answered $<75 \%$ of the HS screening items were further excluded, leaving a sample size of $N=417$. Missing values were analyzed and replaced by imputed mean scores.

\section{Instruments}

\section{Housing Status}

In order to assign participants into groups regarding their housing status, their predominant housing situation 30 days prior to admission was examined. Housing status was categorized into four groups: (1) domiciled patient group (domiciled, including rented apartment, residential property), (2) patient group in socio-therapeutic facilities (facilities, including assisted housing, therapeutic shared apartment and special-care home), (3) patient group sleeping at friends' or acquaintances' places (shared-flat), and (4) homeless patient group (homeless, including literally homeless, emergency shelter, homeless shelter, refugee shelter, and women's shelter).

\section{Socio-Demographic Variables}

A structured interview conducted by trained interviewers collected information on socio-demographic variables of gender, age, marital status, parenthood as well as education and employment. Mental disorder diagnoses were based on existing discharge records and provided by psychiatric clinicians on the basis of ICD-10 criteria (33).

\section{Housing Satisfaction Screening}

A subjective screening was conducted to acquire measures of HS. The compilation of the screening items was based 
on the expertise of different professional groups, including doctors, social workers, and caregivers. In a short test phase, patients evaluated the items in regard to comprehensibility. The screening consisted of 25 items addressing several aspects of HS, including contacts, satisfaction with certain housing aspects such as security or accessibility and subjective assessments on the interplay of housing and psychological and physical wellbeing. Respondents were asked to rate the items in terms of accordance with the presented statement on a four-point Likert-scale ranging from "doesn't apply at all" to "completely applicable."

\section{Statistical Analysis}

All statistical analyses were conducted using IBM SPSS Version 23.0 (34). Standard descriptive analyses of socio-demographic variables were calculated depending on the data scales. The Chisquare test of independence was performed to determine if there is a statistically significant relationship between housing status and suitable socio-demographic variables. Fisher's exact test was used when sample sizes were small and the observed value in the contingency table was less than five, ANOVA was performed in case of metric variables.

In order to assess HS, an exploratory principal component analysis (PCA) was conducted to extract the most important factors of the subjective screening. Subsequently, a Promax rotation was run because correlations between the dimensions were assumed. Ten items had to be excluded because they were undirected and couldn't be linked to an either negative or positive value judgment. A total of 15 items were examined, and data from all participants who completed the screening were included $(N=417)$. Reliability analyses were conducted using Cronbach's alpha to assess the internal consistency of each factor. A sum score of the relevant items was calculated for each participant as the mathematical expression of housing satisfaction.

To examine the impact of housing status on HS, a one-way analysis of variance (ANOVA) was conducted on the overall sum scores as well as on each factor alone. Shapiro-Wilk test was used to check the data distribution, and Levene's test examined homogeneity of variance. Welch's ANOVA was performed and interpreted when the classical ANOVA assumption of homogeneity of variance was violated. Games-Howell post-hoc analysis was run to gain differentiated information on group differences in HS.

\section{RESULTS}

\section{Housing Status}

At the time of data collection, $62.4 \%$ of the participants were domiciled $(N=260), 16.3 \%$ lived in socio-therapeutic facilities $(N=68), 10.3 \%$ lived in shared flats $(N=43)$, and $11.0 \%$ were homeless $(N=46)$.

\section{Socio-Demographic Background}

The average age was 42.11 years, ranging from 18 to 89 . The sample included 178 (42.7\%) women and 238 (57.1\%) men, one person identified themselves as other (0.2\%). $27.9 \%$ were married or in a relationship, and $36.9 \%$ reported to have at least one child. The majority of participants had a school diploma (86.7\%). More than one third had no professional education (37.0\%) and 77.8\% were unemployed.

The participants differed significantly regarding age, school, and professional education and employment status.

As Table 1 shows, domiciled patients were likely to be male, older, in a relationship, to have at least one child, to have graduated from school as well as from a professional education, to be employed and to have a mood disorder. The sharedflat group did not show relevant differences from domiciled patients in terms of gender, family status, school education, and employment status as well as mood disorder diagnosis, but showed less professional education and included younger participants with fewer children. Homeless and facilities groups were more often male, single, and had no school diploma and professional education. Though unemployment was very high in all groups, facilities and homeless comprised the highest percentages with around 95\%. They also showed higher rates of substance dependence, while diagnoses of psychosis, substance abuse, and intellectual disabilities was relatively high in all groups except domiciled.

\section{Factors of Housing Satisfaction}

A PCA was performed to identify the primary domains of HS. One item was ruled out due to insufficient correlations with other items, leaving 14 items for the analysis. Kaiser-Meyer-Olkin measure of sampling adequacy was 0.87 , indicating a good factor analysis. Bartlett's test of sphericity represented sufficiently large correlations between items $(p<0.001)$. Factors were identified by eigenvalues over 1.0 and their explained variability above $10 \%$ $(35,36)$.

The Promax-rotated PCA revealed empirical justification for retaining a two-factor solution including 12 items. The first factor accounted for $43.7 \%$ of the variance in HS and was labeled psychological and physical distress. It included seven items regarding subjective estimations on the extent of housing situation impacts on physical and emotional wellbeing. The second factor, housing comfort, contributed $11.2 \%$ to the overall explained variability. Its five items describe satisfaction with certain aspects of the current housing. All item loadings were above 0.5 in their assigned factor. Table 2 shows the factor loadings of each item. Internal consistency was high for the first factor, Cronbach's alpha $=0.86$, and acceptable for factor two, Cronbach's alpha $=0.79$. Together, the factors accounted for $54.9 \%$ of the variance in HS.

\section{Housing Satisfaction}

A one-way ANOVA was performed to assess the effects of housing status on HS. Data was not normally distributed (Shapiro-Wilk test, $p<0.05$ ). However, the ANOVA is robust against the violation of that requirement in case of a sufficiently large sample size $(N \geq 30)$. Furthermore, data violated the assumption of homogeneity of variances (Levene's test, $p=0.001$ ) and thus, Welch's ANOVA results were interpreted.

As can be seen in Table 3, the level of overall HS differed significantly for the different types of housing status $(p<0.001)$. Games-Howell post-hoc analysis revealed significant differences between HS of all four groups. 
TABLE 1 | Group distributions and corresponding test results of socio-demographic variables.

\begin{tabular}{|c|c|c|c|c|c|}
\hline $\begin{array}{l}\text { Variable } \\
(N=417)\end{array}$ & $\begin{array}{l}\text { Domiciled group } \\
\qquad(N=260)\end{array}$ & $\begin{array}{l}\text { Facilities group } \\
\qquad(N=68)\end{array}$ & $\begin{array}{l}\text { Shared-flat group } \\
\qquad(N=43)\end{array}$ & $\begin{array}{l}\text { Homeless group } \\
\qquad(N=46)\end{array}$ & $\begin{array}{c}\text { ANOVA, Chi-square and } \\
\text { Cramer's } \boldsymbol{V} \\
\text { or Fisher's exact test }\end{array}$ \\
\hline Gender: Female & 119 (45.8\%) & 27 (39.7\%) & $20(46.5 \%)$ & $12(26.1 \%)$ & $p=0.156$ \\
\hline Age (in years) & $44.95(S D=14.47)$ & $41.09(S D=15.51)$ & $31.56(S D=11.23)$ & $37.43(S D=13.73)$ & $F_{(1,415)}=38.91, p<0.001$ \\
\hline Family status ${ }^{1}$ & & & & & $p=0.006$ \\
\hline Married & $36(14.1 \%)$ & $4(6.0 \%)$ & 7 (16.3\%) & $4(9.1 \%)$ & \\
\hline In a relationship & 43 (16.9\%) & $5(7.5 \%)$ & $12(27.9 \%)$ & $3(6.8 \%)$ & \\
\hline Divorced/in separation & $50(19.6 \%)$ & $8(11.9 \%)$ & $3(7.0 \%)$ & $10(22.7 \%)$ & \\
\hline Widowed & $10(3.9 \%)$ & $4(6.0 \%)$ & - & $1(2.3 \%)$ & \\
\hline Single & $116(45.5 \%)$ & $46(68.7 \%)$ & $21(48.8 \%)$ & $26(59.1 \%)$ & \\
\hline At least one child & 106 (41.4\%) & 24 (35.8\%) & 9 (20.9\%) & 15 (32.6\%) & $\begin{array}{c}\chi_{(3)}^{2}=7.26, p=0.064 \\
\text { Cramer's } V=0.133 \\
p=0.064\end{array}$ \\
\hline School education ${ }^{2}$ & & & & & $p<0.001$ \\
\hline $\begin{array}{l}\text { Advanced education (13 years of } \\
\text { school) }\end{array}$ & 105 (41.2\%) & $8(12.7 \%)$ & $15(35.7 \%)$ & $14(31.3 \%)$ & \\
\hline $\begin{array}{l}\text { Intermediate diploma (10 years of } \\
\text { school) }\end{array}$ & $86(33.7 \%)$ & $25(39.7 \%)$ & $14(33.3 \%)$ & $9(20.0 \%)$ & \\
\hline $\begin{array}{l}\text { Basic school qualification (9 years of } \\
\text { school) }\end{array}$ & 42 (16.5\%) & $13(20.6 \%)$ & $8(19.0 \%)$ & $8(17.8 \%)$ & \\
\hline Special needs school graduation & $2(0.8 \%)$ & $2(3.2 \%)$ & - & - & \\
\hline No school diploma & $20(7.8 \%)$ & 15 (23.8\%) & 5 (11.9\%) & $14(31.3 \%)$ & \\
\hline Professional education ${ }^{3}$ & & & & & $p<0.001$ \\
\hline University/college & $55(21.8 \%)$ & 2 (3.0\%) & $6(14.0 \%)$ & $5(11.1 \%)$ & \\
\hline Apprenticeship & 136 (54.0\%) & 26 (39.4\%) & $14(32.6 \%)$ & $12(26.7 \%)$ & \\
\hline None & $61(24.2 \%)$ & 38 (57.8\%) & $23(53.5 \%)$ & $28(62.2 \%)$ & \\
\hline Employment status ${ }^{1}$ & & & & & $p<0.001$ \\
\hline Full-time & 34 (13.4\%) & $1(1.5 \%)$ & $3(7.0 \%)$ & $2(4.4 \%)$ & \\
\hline Half-time & $13(5.1 \%)$ & $1(1.5 \%)$ & $3(7.0 \%)$ & - & \\
\hline In training & $4(1.6 \%)$ & - & $1(2.3 \%)$ & - & \\
\hline Pensioned & $26(10.2 \%)$ & $2(3.0 \%)$ & $1(2.3 \%)$ & - & \\
\hline Unemployed & 177 (69.7\%) & $63(94.0 \%)$ & 35 (81.4\%) & 43 (95.6\%) & \\
\hline \multicolumn{6}{|l|}{ Diagnoses } \\
\hline Organic mental disorders & $15(5.8 \%)$ & $5(7.4 \%)$ & - & $1(2.2 \%)$ & \\
\hline Psychosis & $55(21.2 \%)$ & 22 (32.4\%) & 15 (34.9\%) & 17 (37.0\%) & \\
\hline Any substance dependence & 96 (36.9\%) & 36 (52.9\%) & 14 (32.6\%) & 26 (56.5\%) & \\
\hline Any substance abuse & 38 (14.6\%) & $14(20.6 \%)$ & $10(23.3 \%)$ & 9 (19.6\%) & \\
\hline Mood disorder & $115(44.2 \%)$ & $8(11.8 \%)$ & $17(39.5 \%)$ & $10(21.7 \%)$ & \\
\hline Anxiety disorder & $12(4.6 \%)$ & $2(2.9 \%)$ & $1(2.3 \%)$ & $1(2.2 \%)$ & \\
\hline Personality disorder & 47 (18.1\%) & 17 (25.0\%) & 9 (20.9\%) & $8(17.4 \%)$ & \\
\hline Intellectual disabilities & $2(0.8 \%)$ & $5(7.4 \%)$ & $2(4.7 \%)$ & $1(2.2 \%)$ & \\
\hline
\end{tabular}

Quantities and percentages are depicted for fulfilled variables ("yes"). N varies due to missing data. Cramer's $V$ is only reported in case of significance.

${ }^{1} N=409 .{ }^{2} N=405 .{ }^{3} N=406$.

Table 3 further shows the averaged HS scores for each group. Level of HS regarding overall scores decreased from domiciled to shared-flat (-3.43, 95\%-CI: [-7.68, 0.82]), from shared-flat to facilities (-0.43, 95\%-CI: [-5.29, 4.42]), and from facilities to homeless (-7.45, 95\%-CI: [-11.44, $-3.47]$ ). Significant group differences in HS were found from domiciled to facilities ( $p=0.005)$, from domiciled to homeless $(p<0.001)$, and from facilities to homeless $(p<0.001)$. The shared-flat group had a significantly higher HS than homeless $(p<0.001)$, but not than domiciled $(p=0.153)$ or facilities $(p=0.995)$.

When differentiating between the two factors, Table 3 illustrates that the same pattern could be found for psychological and physical distress $(p<0.001)$. Satisfaction hereby decreased significantly from domiciled to facilities $(p=0.001)$, from domiciled to homeless $(p<0.001)$ and facilities to homeless $(p=0.012)$, while shared-flat only scored significantly higher than homeless $(p=0.013)$. When regarding the second factor 
TABLE 2 | Factor loadings of the subjective screening items on examined housing satisfaction domains.

\begin{tabular}{|c|c|c|}
\hline Item & $\begin{array}{l}\text { Factor 1: } \\
\text { Psychological and } \\
\text { physical distress }\end{array}$ & $\begin{array}{l}\text { Factor 2: } \\
\text { Housing } \\
\text { comfort }\end{array}$ \\
\hline $\begin{array}{l}\text { Due to my housing situation, I have } \\
\text { experienced violence. }\end{array}$ & 0.698 & \\
\hline $\begin{array}{l}\text { My housing situation is my biggest } \\
\text { problem at the moment. }\end{array}$ & 0.790 & \\
\hline $\begin{array}{l}\text { I consider my housing situation to } \\
\text { be very burdensome. }\end{array}$ & 0.775 & \\
\hline $\begin{array}{l}\text { My housing situation worsened my } \\
\text { mental condition. }\end{array}$ & 0.839 & \\
\hline $\begin{array}{l}\text { My housing situation worsened my } \\
\text { physical condition. }\end{array}$ & 0.842 & \\
\hline $\begin{array}{l}\text { Due to my housing situation, I feel } \\
\text { lonely and excluded. }\end{array}$ & 0.611 & \\
\hline $\begin{array}{l}\text { I am satisfied with the safety of my } \\
\text { housing situation. }\end{array}$ & & 0.770 \\
\hline $\begin{array}{l}\text { My housing situation offers } \\
\text { sufficient opportunities for quiet } \\
\text { and relaxation. }\end{array}$ & & 0.733 \\
\hline $\begin{array}{l}\text { I am satisfied with the possibilities } \\
\text { for body care at my housing. }\end{array}$ & & 0.665 \\
\hline $\begin{array}{l}\text { I am content with the amount of } \\
\text { privacy at my housing. }\end{array}$ & & 0.695 \\
\hline $\begin{array}{l}\text { I am satisfied with the accessibility } \\
\text { of my housing in regard to my } \\
\text { work place, friends and family. }\end{array}$ & & 0.782 \\
\hline $\begin{array}{l}\text { I feel restricted by the rules of my } \\
\text { residential facility. }\end{array}$ & 0.562 & \\
\hline
\end{tabular}

The items were translated from German into English for depiction purposes only. Items were named in order of appearance in the original subjective screening. Factor loadings are depicted above 0.20 .

shown in Table 3, housing comfort showed diverging trends $(p<0.001)$. Significant declines were found from domiciled to homeless $(p<0.001)$, from facilities to homeless $(p<0.001)$, and shared-flat to homeless $(p<0.001)$. Shared-flat could not be differentiated from domiciled $(p=0.403)$ nor from facilities $(p=0.999)$. Additionally, there were no differences between domiciled and facilities $(p=0.264)$, implying that only homeless differed significantly from all other groups in terms of housing comfort.

\section{DISCUSSION}

\section{Main Findings}

To our knowledge, this is the first study to comprehensively evaluate HS across all housing situations of mentally ill people, rather than simply homeless vs. domiciled. As hypothesized, the results demonstrate a decrease in HS when the housing situation becomes less normative, which contributes to findings of other studies $(12,14,19,25)$. HS was found to be significantly higher for domiciled and shared-flat categories, than facilities, and finally, people in the homeless category reported the lowest satisfaction. These findings emphasize the heavy psychological burden of precarious living conditions and further illustrate the negative impact of homelessness on psychological wellbeing. Interestingly, participants living with friends or acquaintances show higher levels of overall HS, despite being considered as precariously housed. This form of housing is less independent and secure, due to a greater potential for conflicts, a need for compromise as well as a greater risk of having to move out in the case of temporary or uncertain leasing agreements. However, the familiarity of living in a household with others and the potentially supportive interactions with flatmates might protect the individuals from feeling psychologically or physically burdened by their housing situation. Additionally, HS of people living in shared flats might be higher due to aspects of autonomy and choice, which is further discussed below. These findings suggest that precarious living circumstances require nuanced analyses and reinforces the need for a more thorough understanding of the impact of different housing forms as well as opportunities for improvement.

When considering the overall scores of HS in all four groups, it is apparent that despite significant variations, the relative differences between group scores do not appear to be exceptionally large (i.e., domiciled-83.5\% vs. shared-flat$-76.3 \%)$. These score proximities might be a result of a similar level of vulnerability and instability in our sample stemming from common mental health risks. Greater social burdens in all four groups, exemplified by exceptionally high unemployment rates, could further explain the lower group differences, as all groups seem to experience social precariousness to some extent. Furthermore, the total HS scores illustrate that no housing group reported a particularly low HS. The facilities group, for instance, achieved $75.4 \%$, and the homeless group scored $59.8 \%$ of the total score. As HS is a subjective experience, it might be influenced by the duration of the current housing situation and the adaptation to its accompanying circumstances. The participants might have experienced several housing interventions due to a long history of mental illness, which could lead to a greater acceptance of housing facilities in general. As continuity of care throughout various elements of the service systems has been positively associated with QoL and greater service satisfaction, it could possibly further have an influence on HS specifically (37). In addition, long-term homelessness might influence the perception of different shelters, such as homeless shelters compared to emergency shelters. Generally, these results can also be understood in terms of the satisfaction paradox, which describes findings of relatively high housing satisfaction despite a low estimation of objective housing quality (38). These authors posit that this inconsistency could derive from resignation and cognitive dissonance caused by a perceived lack of opportunity for change. Housing should therefore be considered as an important resource in therapeutic processes.

The overall group differences are particularly apparent in the first factor on psychological and physical distress. The potential for constructively dealing with mental and physical health issues, social exclusion, restrictions, and negative experiences is notably lower for homeless patients, probably because homelessness is often accompanied by a lack of beneficial support and connection to helpful resources, while basic needs and the anticipation 
TABLE 3 | Descriptive housing satisfaction, including mean scores and standard deviation, and Welch's ANOVA results.

\begin{tabular}{|c|c|c|c|c|c|}
\hline $\begin{array}{l}\text { Housing satisfaction } \\
(N=417)\end{array}$ & $\begin{array}{l}\text { Domiciled group } \\
\qquad(N=260)\end{array}$ & $\begin{array}{l}\text { Facilities group } \\
\qquad(N=68)\end{array}$ & $\begin{array}{l}\text { Shared-flat group } \\
\qquad(N=43)\end{array}$ & $\begin{array}{l}\text { Homeless group } \\
\qquad(N=46)\end{array}$ & Welch's F \\
\hline $\begin{array}{l}\text { Overall } \\
(\max =48)\end{array}$ & $\begin{array}{l}40.06 \\
(7.16)\end{array}$ & $\begin{array}{l}36.19 \\
(8.51)\end{array}$ & $\begin{array}{c}36.63 \\
(10.07)\end{array}$ & $\begin{array}{l}28.73 \\
(7.61)\end{array}$ & $\begin{array}{c}\text { Welch's } \\
F_{(3,99.29)}=30.70 \\
p<0.001\end{array}$ \\
\hline $\begin{array}{l}\text { Factor } 1 \\
(\max =28)\end{array}$ & $\begin{array}{l}23.81 \\
(4.75)\end{array}$ & $\begin{array}{l}20.90 \\
(5.66)\end{array}$ & $\begin{array}{l}21.47 \\
(6.29)\end{array}$ & $\begin{array}{l}17.45 \\
(5.86)\end{array}$ & $\begin{array}{c}\text { Welch's } \\
F_{(3,98.19)}=19.63, \\
p<0.001\end{array}$ \\
\hline $\begin{array}{l}\text { Factor } 2 \\
(\max =20)\end{array}$ & $\begin{array}{l}16.24 \\
(3.36)\end{array}$ & $\begin{array}{l}15.29 \\
(3.94)\end{array}$ & $\begin{array}{l}15.16 \\
(4.32)\end{array}$ & $\begin{array}{l}11.28 \\
(4.34)\end{array}$ & $\begin{array}{c}\text { Welch's } \\
F_{(3,98.13)}=18.32, \\
p<0.001\end{array}$ \\
\hline
\end{tabular}

of discrimination become more present and important (39). Participants in socio-therapeutic facilities, however, also show lower levels of satisfaction in the first factor specifically, although these facilities are meant to target those aspects and to support their clients with social and health-related issues (40).

These group differences in HS might be explained by research on housing for mentally ill people, which proposes that characteristics of independence, choice, and control are important for psychopathology and QoL (23, 41-43). Further studies suggest that independent living in one's own dwelling increases HS in formerly homeless samples as opposed to dependent housing or group homes $(11,44)$. While research does concentrate on supported housing for mentally ill people with experiences of homelessness, studies on the effectiveness of supported housing forms for non-homelessness samples are scarce (40). However, the S3 guideline for psychosocial therapies for severe mental disorders (40) suggests avoiding permanent and high levels of institutionalization for people with mental illness in general as it increases negative or unwanted side effects. The separation of housing subvention and psychiatric or social care is highlighted and independent housing promoted as a means of enabling individual support regardless of residence.

These characteristics could play a role in this study's findings of diverging HS, because homeless people experience limited choices due to poverty and inequity, while patients in socio-therapeutic facilities deal with less autonomy and imposed rules (45). On the contrary, qualitative assessments of housing preference concluded that living in supported housing was associated with privacy and control as well as feeling secure and safe $(46,47)$. Furthermore, when examining the socio-demographic background, these participant groups show higher rates of psychosis and substance dependence and were less likely to be in a partnership or married. A difficult housing situation may be more salient in the case of people with greater psychological symptomatology or a scarce sense of wellbeing. Additionally, psychotic symptoms and substance procurement present competing priorities, which may overshadow concerns with one's housing (39). Conversely, previous negative housing experiences could amplify present symptomatology and substance use.

As several studies point out, there is a strong preference among persons with mental illness for living in their own apartment as it implies more independence and autonomy (43, 48). However, whether these aspects moderated the perception of psychological and physical stresses in this sample could not be analyzed in the current study. The relationship between those stresses and the suggested characteristics of independence, choice, and control as well as their role in socio-therapeutic facilities need to be investigated further. Potential moderating effects of the proposed characteristics could be integrated into HS measures to further explore the interrelation of the different factors.

The second subscale, housing comfort, represents housing features that ensure basic qualitative requirements of housing. Only the homeless group reported significantly lower satisfaction, whereas the groups domiciled, facilities, and shared-flat did not show any group differences. Since homeless people do not experience proper housing in any form, basic needs for safety, relaxation, hygiene, privacy, and accessibility in housing can naturally not be satisfied.

These findings support approaches such as Housing First to reduce homelessness and increase stable housing conditions (49). This intervention prioritizes the immediate and unconditional access to appropriate housing before further therapeutic support and focuses on recovery-oriented and support-oriented individual needs to build a basis for increased choice and decision freedom $(49,50)$.

\section{Limitations}

The findings cannot be generalized to other regions because situational and local supply conditions can have an impact on housing opportunities, mental health risks, living circumstances, support networks, and health insurance for the targeted group $(25,31,51)$. Secondly, the homeless sample is only specifically representative of those in psychiatric hospital care. While a high amount of homeless people suffer from mental illnesses, only a small number of them manage to seek professional help due to a high severity of symptoms and problematic living circumstances $(18,28)$. Affected individuals without psychiatric care might report diverging needs and challenges in everyday life. Additionally, housing forms of eligible patients who did not participate in the study could not be assessed due to refusal to participate, short lengths of stay or inability to consent. Potential associations between participation and housing form 
might impact our results and their representativeness and interpretation. Schreiter et al. (31) discuss differences between participants and non-participants in terms of age, gender, and certain diagnoses in more detail. Further, while acceptable reliability of the HS instrument was achieved and objectivity was ensured by standardized administration situations, validity of the developed scale has not been examined. To our knowledge, no validated German instrument on housing satisfaction would have been appropriate for all housing forms in our sample. The use of this individually tailored instrument limits psychometric testing and interpretation. A comparison to further HS research should be sensitive to possible impacts of differing measurements.

Given these findings on psychological and physical distress imposed by different housing situations, qualitative approaches on HS research might be appropriate for further exploration of this theme, providing more detailed insight into the reality of life of precariously housed persons.

\section{CONCLUSION}

The insecurity and stress of homelessness and precarious housing contribute a serious additional burden to the lives of highly vulnerable mentally ill people. The findings highlight the importance of interventions targeting homelessness among psychiatric patients. The reported psychological and physical stress among people in therapeutic facilities underlines the need for adequate psychological support in such housing forms, to enhance HS among its clients.

\section{REFERENCES}

1. Salize H, Rössler W, Becker T. Mental health care in Germany: current state and trends. Eur Arch Psychiatry Clin Neurosci. (2007) 257:92103. doi: 10.1007/s00406-006-0696-9

2. Richter D, Hoffmann H. Die Deinstitutionalisierung der psychiatrischen Versorgung ist nicht gelungen [The deinstitutionalization of psychiatric care did not succeed]. Sozialpsychiatr Inf. (2016) 2:11-3. doi: 10.1024/2297-6965/a000109

3. Newman SJ. Housing attributes and serious mental illness: implications for research and practice. Psychiatr Serv. (2001) 52:1309-17. doi: 10.1176/appi.ps.52.10.1309

4. Richter D, Eikelmann B, Reker T. Arbeit, einkommen, partnerschaft: die soziale exklusion psychisch kranker menschen [Work, Income, partnership: the social exclusion of persons with mental illness]. Das Gesundheitswesen. (2006) 68:704-7. doi: 10.1055/s-2006-927288

5. Morse G, Calsyn RJ. Mentally disturbed homeless people in St Louis: needy, willing, but underserved. Int J Mental Health. (1986) 14:7494. doi: 10.1080/00207411.1985.11449011

6. Schreiter S, Bermpohl F, Krausz MR, Leucht S, Rössler W, Schouler-Ocak M, et al. The prevalence of mental illness in homeless people in Germany. Dtsch Arztebl. (2017) 114:665-72. doi: 10.3238/arztebl.2017.0665

7. Jenderny S, Schreiter J, Steinhart I. Psychiatrische wohnheime in Deutschland - transparenz und strukturen [Psychiatric facilities in Germany - transparency and structures]. Psychiatr Prax. (2020) 47:260-6. doi: 10.1055/a-1126-1103

8. Steinhart I, Jenderny S, Schreiter J. (Geschlossene) besondere Wohnformen als unverzichtbarer Teil der regionalen Verbundstrukturen in Deutschland [(Closed) Psychiatric homes as part of the regional networks in Germany]? Psychiatr Prax. (2020) 47:370-5. doi: 10.1055/a-1126-1214

\section{DATA AVAILABILITY STATEMENT}

The data analyzed in this study is subject to the following licenses/restrictions: data security reasons (identifiable data). Requests to access these datasets should be directed to Stefanie Schreiter (Stefanie.schreiter@charite.de).

\section{ETHICS STATEMENT}

The study involving human participants were reviewed and approved by local ethics committee of the CharitéUniversitätsmedizin Berlin. The patients/participants provided their written informed consent to participate in this study.

\section{AUTHOR CONTRIBUTIONS}

SS and SG were responsible for drafting and revising the original study protocol, they were the chief investigators and had overall responsibility for management of the trial, they delivered the training to the interviewers. MS-O revised the original study protocol and provided additional clinical supervision. EW wrote the framework and analysis plan. EW and JM analyzed the data. EW wrote the first draft of the report. SS, SG, and JM revised subsequent draft. All authors contributed to and approved the final report.

\section{ACKNOWLEDGMENTS}

We want to thank all patients for their participation and talking freely about their challenges and sharing their experience.

9. Lehman AF. A Quality of Life Interview for the chronically mentally ill. Eval Prog Plann. (1988) 11:51-62. doi: 10.1016/0149-7189(88)90033-X

10. Sullivan G, Burnam A, Koegel P, Hollenberg J. Quality of life of homeless persons with mental illness: results from the course-of-homelessness study. Psychiatr Serv. (2000) 51:1135-41. doi: 10.1176/appi.ps.51.9.1135

11. Wolf J, Burnam A, Koegel P, Sullivan G, Morton S. Changes in subjective quality of life among homeless adults who obtain housing: a prospective examination. Soc Psychiatry Psychiatr Epidemiol. (2001) 36:3918. doi: 10.1007/s001270170029

12. Lehman AF, Possidente S, Hawker F. The quality of life of chronic patients in a state hospital and in community residences. Psychiatr Serv. (1986) 37:901-07. doi: $10.1176 /$ ps.37.9.901

13. Lehman AF, Slaughter J, Myers C. Quality of life in alternative residential settings. Psych Quart. (1991) 62:35-49. doi: 10.1007/BF01958837

14. Sullivan G, Wells K, Leake B. Quality of life of seriously mentally ill persons in Mississippi. Psychiatric Services. (1991) 42:752-55. doi: 10.1176/ps.42.7.752

15. Lehman AF, Ward NC, Linn LS. Chronic mental patients: the quality of life issue. Am J Psychiatry. (1982) 139:1271-76. doi: 10.1176/ajp.139.10.1271

16. Bassuk EL, Rubin L, Lauriat A. Is homelessness a mental health problem? Am J Psychiatry. (1984) 141:1546-49. doi: 10.1176/ajp.141.12.1546

17. Hubley A, Russel L, Palepu A, Hwang S. Subjective quality of life among individuals who are homeless: a review of current knowledge. Soc Indic Res. (2014) 115:509-24. doi: 10.1007/s11205-012-9998-7

18. Reker T, Eikelmann B. Wohnungslosigkeit, psychische Erkrankungen und psychiatrischer Versorgungsbedarf [Homelessness, mental illness and demands for psychiatric care]. Dtsch Arztebl. (1997) 21:1439-41.

19. Lehman AF, Kernan E, DeForge BR, Dixon L. Effects of homelessness on the quality of life of persons with severe mental illness. Psychiatr Serv. (1995) 46:922-6. doi: 10.1176/ps.46.9.922 
20. Thomas Y, Gray MA, McGinty S. An exploration of subjective wellbeing among people experiencing homelessness: a strengths-based approach. Soc Work Health Care. (2012) 51:780-97. doi: 10.1080/00981389.2012.686475

21. Schreiter S, Bermpohl F, Schouler-Ocak M, Krausz MR, Rössler W, Heinz A, et al. Bank account ownership and access among in-patients in psychiatric care in Berlin, Germany - a cross-sectional patient survey. Front Psychiatry. (2020) 11:508. doi: 10.3389/fpsyt.2020.00508

22. Schreiter S, Heidrich S, Heinz A, Rössler W, Krausz MR, Schouler-Ocak M, et al. Schulden, Kredite und unbezahlte Rechnungen unter Nutzer*Innen teilstationärer und stationärer psychiatrischer Behandlung in Berlin [Debts, loans and unpaid bills among day patients and inpatients in psychiatric care in Berlin, Germany]. Nervenarzt. (2020). doi: 10.1007/s00115-020-01013-9

23. Carling PJ. Major Mental illness, housing, and supports: the promise of community integration. Am Psychol. (1990) 45:96975. doi: 10.1037/0003-066X.45.8.969

24. Vila-Rodriguez F, Panenka W, Lang D, Thornton A, Vertinsky T, Wong $\mathrm{H}$, et al. The hotel study: multimorbidity in a community sample living in marginal housing. Am J Psychiatry. (2013) 170:141322. doi: 10.1176/appi.ajp.2013.12111439

25. Salize HJ, Horst A, Dillmann-Lange C, Killmann U, Stern G, Wolf I, et al. Wie beurteilen psychisch kranke Wohnungslose ihre Lebensqualität [How do mentally ill homeless people perceive their quality of life]? Psychiatr Praxis. (2001) 28:75-80. doi: 10.1055/s-2001-11582

26. Patterson M, Moniruzzaman A, Palepu A, Zabkiewicz D, Frankish CJ, Krausz M, et al. Housing First improves subjective quality of life among homeless adults with mental illness: 12-month findings from a randomized controlled trial in Vancouver, British Columbia. Soc Psychiatry Psychiatr Epidemiol. (2013) 48:1245-59. doi: 10.1007/s00127-013-0719-6

27. Salize HJ, Dillmann-Lange C, Kentner-Figura B, Reinhard I. Drohende Wohnungslosigkeit und psychische Gefährdung [Threatened homelessness and mental disorders]. Nervenarzt. (2006) 77:1345-54. doi: 10.1007/s00115-005-1997-3

28. Kyle T, Dunn JR. Effects of housing circumstances on health, quality of life and healthcare use for people with severe mental illness: a review. Health Soc Care Community. (2008) 16:1-15. doi: 10.1111/j.1365-2524.2007.00723.x

29. Tsai J, Mares AS, Rosenheck RA. Housing satisfaction among chronically homeless adults: identification of its major domains, changes over time, and relation to subjective well-being and functional outcomes. Community Ment Health J. (2012) 48:255-63. doi: 10.1007/s10597-011-9385-x

30. Vera-Toscano E, Ateca-Amestoy V. The relevance of social interactions on housing satisfaction. Soc Indic Res. (2008) 86:257-74. doi: 10.1007/s11205-007-9107-5

31. Schreiter S, Heidrich S, Zulauf J, Saathoff U, Brückner A, Majic T, et al. Housing situation and healthcare for patients in a psychiatric centre in Berlin, Germany: a cross-sectional patient survey. BMJ Open. (2019) 9:e032576. doi: 10.1136/bmjopen-2019-032576

32. Schreiter S, Fritz FD, Rössler W, Majic T, Schouler-Ocak M, Krausz MR, et al. Wohnsituation von Menschen mit Substanzgebrauchsstörung im akut-psychiatrischen Behandlungssetting in Berlin - eine querschnittliche Patientenbefragung [Housing situation among people with substance use disorder in a psychiatric centre in Berlin, Germany - a cross-sectional patient survey]. Psychiat Prax. (2020) 47:1-5. doi: 10.1055/a-1290-5091

33. Graubner B. ICD-10-GM Internationale Statistische Klassifikationen der Krankheiten und Verwandter Gesundheitsprobleme [ICD-10-GM International Statistical Classification of Diseases and Related Health Issues]. Köln: Deutscher Ärzteverlag (2013).

34. IBM Corp. IBM SPSS Statistics for Windows, Version 23.0. Armonk, NY: IBM Corp. (2015).

35. Guttman L. Some necessary conditions for common-factor analysis. Psychometrika. (1954) 19:149-61. doi: 10.1007/BF02289162

36. Kaiser HF. The application of electronic computers to factor analysis. Educ Psychol Meas. (1960) 20:141-51. doi: 10.1177/001316446002000116

37. Adair CE, McDougall GM, Mitton CR, Joyce AS, Wild TC, Gordon A, et al. Continuity of care and health outcomes among persons with severe mental illness. Psychiatr Serv. (2005) 56:1061-69. doi: 10.1176/appi.ps.56.9.1061

38. Glatzer W. Lebensqualität und subjektives Wohlbefinden. Ergebnisse sozialwissenschaftlicher Untersuchungen [Quality of Life subjective
Wellbeing. Results from a social science investigation] In: Bellebaum A, editor. Glück und Zufriedenheit [Happiness Contentment]. Wiesbaden: VS Verlag für Sozialwissenschaften (1992). p. 49-85.

39. O'Carroll A, Wainwright D. Making sense of street chaos: an ethnographic exploration of homeless people's health service utilization. Int J Equity Health. (2019) 18:113. doi: 10.1186/s12939-019-1002-6

40. Gühne U, Weinmann S, Riedel-Heller S, Becker T, Aderholz VV, Bechdolf A, et al. Kurzfassung der S3-Leitlinie Psychosoziale Therapien bei schweren psychischen Erkrankungen [Short version of the S3-guideline psychosocial therapies for severe mental disorder]. Deutsche Gesellsc Psychiatr Psychother Psychosom Nervenheil. (2019). Available online at: https://www.dgppn.de/ Resources/Persistent/4a081f97b24d101a36bd970d5fd3823d562404cd/S3-LLPsychosozTherapien-Kurzfassung.pdf

41. Greenwood RM, Schaefer-McDaniel NJ, Winkel G, Tsemberis SJ. Decreasing psychiatric symptoms by increasing choice in services for adults with histories of homelessness. Am J Community Psychol. (2005) 36:22338. doi: 10.1007/s10464-005-8617-z

42. Nelson G, Sylvestre J, Aubry T, George L, Trainor JN. Housing choice and control, housing quality, and control over professional support as contributors to the subjective quality of life and community adaptation of people with severe mental illness. Adm Policy Ment Health. (2007) 34:89100. doi: 10.1007/s10488-006-0083-x

43. Richter D, Hoffmann H. Preferences for independent housing of persons with mental disorders: systematic review and meta-analysis. Adm Policy Ment Health. (2017) 44:817-23. doi: 10.1007/s10488-017-0791-4

44. Schutt RK, Goldfinger SM, Penk WE. Satisfaction with residence and with life. When homeless mentally ill persons are housed. Eval Prog Plann. (1997) 20:185-94. doi: 10.1016/S0149-7189(96)00049-3

45. LaGory M, Fitzpatrick K, Ritchey F. Life chances and choices: assessing quality of life among the homeless. Sociol Q. (2001) 42:633-51. doi: 10.1525/tsq.2001.42.4.633

46. Watson J, Fossey E, Harvey C. A home but how to connect with others? A qualitative meta-synthesis of experiences of people with mental illness living in supported housing. Health Soc Care Community. (2019) 27:54664. doi: $10.1111 /$ hsc. 12615

47. Tsai J, Bond GR, Salyers MP, Godfrey JL, Davis KE. Housing preferences and choices among adults with mental illness and substance use disorders: a qualitative study. Community Mental Health J. (2010) 46:381-8. doi: 10.1007/s10597-009-9268-6

48. Piat M, Lesage A, Boyer R, Dorvil H, Couture A, Grenier G, et al. Housing for persons with serious mental illness: consumer and service provider preferences. Psychiatr Serv. (2008) 59:1011-7. doi: 10.1176/ps.2008.59. 9.1011

49. Aubry T, Nelson G, Tsemberis S. Housing first for people with severe mental illness who are homeless: a review of the research and findings from the at home - Chez soi Demonstration Project. Can J Psychiatry. (2015) 60:46774. doi: 10.1177/070674371506001102

50. Gühne U, Deutsche Gesellschaft für Psychiatrie und Psychotherapie, Psychosomatik und Nervenheilkunde. "Systeminterventionen" [System Interventions]. In: Gühne U, Weinmann S, Riedel-Heller SG, Becker T, editors. S3-Leitlinie Psychosoziale Therapien bei Schweren Psychischen Erkrankungen [S3-guideline Psychosocial Therapies for Severe Mental Disorders]. Berlin: Springer (2019). p. 91-193.

51. Gruebner O, Rapp MA, Adli M, Kluge U, Galea S, Heinz A. Cities and mental health. Dtsch Arztebl. (2017) 114:121-27. doi: 10.3238/arztebl.2017.0121

Conflict of Interest: The authors declare that the research was conducted in the absence of any commercial or financial relationships that could be construed as a potential conflict of interest.

Copyright (C) 2021 Gutwinski, Westerbarkey, Schouler-Ocak, Moran and Schreiter. This is an open-access article distributed under the terms of the Creative Commons Attribution License (CC BY). The use, distribution or reproduction in other forums is permitted, provided the original author(s) and the copyright owner(s) are credited and that the original publication in this journal is cited, in accordance with accepted academic practice. No use, distribution or reproduction is permitted which does not comply with these terms. 